\title{
Study of obstetric outcome in pregnancies with intrauterine growth retardation
}

\author{
Surbhi Sinha*, Vilas N. Kurude
}

Department of Obstetrics and Gynecology, Grant Government Medical College, Mumbai, Maharashtra, India

Received: 04 March 2018

Accepted: 01 April 2018

\section{*Correspondence:}

Dr. Surbhi Sinha,

E-mail: sur.sinz@gmail.com

Copyright: ( ) the author(s), publisher and licensee Medip Academy. This is an open-access article distributed under the terms of the Creative Commons Attribution Non-Commercial License, which permits unrestricted non-commercial use, distribution, and reproduction in any medium, provided the original work is properly cited.

\begin{abstract}
Background: The prevalence of low birth weight affects approximately 3-10\% of live-born newborns in developed countries and 15-20\% of newborns.in developing countries. The most common cause of low birth weight is considered to be intrauterine foetal growth restriction. IUGR being an outcome of multiple etiologies and as indicated by the literature survey varies upon population statistics in terms of economic status as well as maternal health conditions.

Methods: This study includes 100 patients with foetal growth restriction in a tertiary health care centre in Mumbai over a period of 11/2 year (Jan 2015 to July2016) and the relevant data of these patients such as indoor registration number, maternal age, parity, antenatal registration and referral details, medical, obstetric, social risk factors and fetomaternal outcome were collected using a predesigned proforma.

Results: Incidence of IUGR in our study population was found to be $2.13 \%$ of which maximum number of cases $(48 \%)$ were seen in the age group of 21-25 years. Low socio-economic group, maternal high-risk factors like Preeclampsia and eclampsia were associated with low Mean Birth weights of babies. Symphysio-fundal height was found to be a sensitive predictor of IUGR and the ratio HC/AC was associated with prediction of type of IUGR ( $\mathrm{p}=0.000$ ). $83 \%$ cases were found to have asymmetric IUGR while $17 \%$ cases had symmetric IUGR. The Perinatal Mortality Rate was found to be 1.92 per 1000 live births with $5 \%$ still births and $8 \%$ neonatal deaths, the most common causes of neonatal death being sepsis $(44.4 \%)$ and respiratory distress syndrome $(44.4 \%)$.

Conclusions: Accurate dating, provision of early registration with regular antenatal checkup, clinico- sonographic evaluation and correlation for fetal growth in high risk patients and strict antepartum surveillance after IUGR has been identified are recommended. Integration of foetal anatomy assessment, amniotic fluid dynamics, uterine, umbilical, and foetal middle cerebral artery Doppler is the most effective approach to differentiate potentially manageable placenta-based Fetal Growth Restriction(FGR) from IUGR due to aneuploidy, non- aneuploid syndromes, and viral infection.
\end{abstract}

Keywords: Asymmetrical IUGR, Intrauterine growth Restriction (IUGR), Small for gestational age (SGA), Symmetrical IUGR

\section{INTRODUCTION}

A definition and classification of IUGR, shared among different countries, has not been yet agreed. Approximately $7 \%$ of pregnancies are complicated by IUGR. The terms IUGR and SGA have often been used synonymously. However, there is a difference in their meanings. The SGA definition is based on the crosssectional evaluation (either prenatal or postnatal) and this term has been used for those neonates whose birth weight is less than the $10^{\text {th }}$ percentile for that particular gestational age or two standard deviations below the population norms on the growth charts. IUGR on the other hand is a clinical definition and applies to neonates 
born with clinical features of malnutrition and in-utero growth restriction, irrespective of their birth weight percentile. A neonate with a birth weight greater than the 10 th percentile will be an IUGR in spite of not being SGA, if the infants have features of malnutrition at birth. ${ }^{1}$

Foetal Growth Restriction is the second leading cause of Perinatal morbidity and mortality, followed only by prematurity. 2,3 IUGR can be symmetrical with low weight, length and head circumference indicative usually of a process with its origin early in pregnancy or asymmetrical with sparing of head circumference and length due to processes occurring later in gestation. The Mortality Rate is 70 to 100 times higher in infants who weigh less than $1,500 \mathrm{~g}(3 \mathrm{lb}, 5 \mathrm{oz}){ }^{4}$ It is very important to make the right diagnosis of IUGR, the cause of their illness, the therapy needed and when it's necessary to find the right time, place and way of birth.

\section{METHODS}

This study includes 100 patients with foetal growth restriction in a tertiary health care centre in Mumbai and the risk factors were studied.

\section{Type of study: Prospective Observational Study}

Setting: General obstetric units of a tertiary healthcare hospital in Mumbai.

Study period: January 2015=October 2016 (one and half year)

\section{Sample size: 100 patients}

Ethics: Study was approved by the ethics committee before commencing.

Consent: Informed, valid, written consent is taken.

\section{Data collection}

Data was collected using a predesigned proforma.

\section{Statistical Analysis}

Data was entered in MS-Excel sheet. Summary measures like percentages were calculated to describe categorical variables.

\section{Inclusion criteria}

- These patients may be booked, unbooked or referred as high-risk cases from other hospitals

- Patients with $>28$ weeks gestation, who were sure of their last menstrual period, or confirmed by atleast one first trimester ultrasound.

- Patients with singleton pregnancies with foetal growth restriction.

\section{Exclusion criteria}

- Patients with unsure dates, irregular menstrual cycles.

- History of consumption of oral contraceptive pills within three months of conception.

- Multiple pregnancies

\section{Procedure}

This is a study of 100 cases of IUGR over a period of $11 / 2$ year in a tertiary health care centre in Mumbai. The relevant data of these patients such as indoor registration number, maternal age, parity, social history was noted. Accordingly, socio- economic status was determined as follows: Lower class- average monthly income < Rs. 1500 Middle class- average monthly income Rs15003000 Higher class- average monthly income> Rs.3000 Menstrual history was noted in cases in which mothers had regular cycles and were sure of their dates, for assessment of gestational age calculated by Naegle's formula. In cases where dates were not known and with irregular cycles, gestational age was calculated by first dating scan done in 1 st trimester. Period of gestation when ANC registration was done, regular or irregular follow up, no. of antenatal visits, weight gain in pregnancy was noted. Any significant medical or obstetric history/ complication was noted. In maternal monitoring- gravidogram was maintained (weight, Pulse, $\mathrm{BP}$, urine albumin, fundal height, abdominal girth). In foetal monitoring- strict Daily Foetal Kick Count (DFKC), and Non-Stress Test (NST)) was done once/ twice daily. BPD, FL, AC and $\mathrm{HC} / \mathrm{AC}$ ratio were measured by ultrasonography. $\mathrm{HC} / \mathrm{AC}$ ratio $>1$ was taken as indicator of asymmetric IUGR. Serial USGs to assess foetal growth, AFI and placental maturity, Colour Doppler and Biophysical Profile were done. Mode of delivery of patient and indications in case of LSCS were noted. Baby details including sex, baby weight, APGAR score at 1 and 5 minutes, New Ballard's Score, colour of hind-water, liquor, neonatal outcome and complications were noted. Finally, maternal and perinatal outcome was determined.

\section{RESULTS}

There were 4674 total deliveries in the study period of 11/2 years from Jan 2015 to

July 2016 and we found 100 cases of IUGR. The incidence of IUGR in our study population was found to be $2.13 \%$ of which maximum number of cases (48\%) were seen in the age group of 21-25 years as this is the usual average age for reproduction in India. Socioeconomically this population was majorly in lower income group category ( $<$ Rs.1000 per month). In the present study, maximum no. of cases $(55 \%)$ were primigravida and most of these cases were registered $(96 \%)$. The cases registered in our hospital with regular follow up showed more mean birth weight of babies than 
the referred ones (registered outside) and the unregistered. Of these, those registered in first trimester showed maximum mean birth weight.

Amongst the high-risk factors associated with IUGR, PIH during the current pregnancy was found to be statistically significant risk factor for IUGR $(\mathrm{p}=0.003)$ and cases with severe PIH and eclampsia had least mean birth weight and subsequently poor perinatal outcomes. Cases with moderate to severe anaemia had more no. of maternal complications like infection and post-partum haemorrhage (Table 1).

Table 1: Maternal high-risk factors associated with IUGR.

\begin{tabular}{|l|l|}
\hline High risk factor & $\%$ \\
\hline Pregnancy Induced Hypertension & 55 \\
\hline Anemia & 30 \\
\hline Febrile Illnes & 10 \\
\hline Idiopathic & 05 \\
\hline Chronic hypertension & 03 \\
\hline h/o Previous IUGR & 06 \\
\hline Heart Disease(Cardiomyopathy) & 02 \\
\hline Undernourished & 03 \\
\hline Abruptioplacenta & 03 \\
\hline Placenta Previa & 02 \\
\hline Fibroid uterus & 03 \\
\hline Hypothyroidism/Hyperthyroidism & 04 \\
\hline Bronchial asthma & 01 \\
\hline Seizure disorder (on anti-epileptics) & 01 \\
\hline h/o first trimester bleeding & 01 \\
\hline Congenital anomalous baby & 04 \\
\hline
\end{tabular}

Other maternal risk factors for IUGR In the present study were febrile Illness, chronic HTN, history of previous IUGR, thyroid disorders, heart disease (cardiomyopathy), undernourishment, bleeding PV in 1 st trimester, fibroid uterus, placenta previa, congenital anomalies and seizure disorder on antiepileptics.

Symphysio-fundal height was found to be a sensitive predictor of IUGR. It was observed that $80 \%$ cases had asymmetrical IUGR with $\mathrm{HC} / \mathrm{AC}$ ratio more than 1 and there was significant association between the ratio $\mathrm{HC} / \mathrm{AC}$ and type of IUGR $(\mathrm{p}=0.000)$.

We found Grade 3 placenta in $77 \%$ cases out of which 87 $\%$ cases had less than 36 weeks gestation suggesting that placental ageing possibly may be the nature's "blackbox mechanism" to predict an earlier intervention for better outcome of the fetus. Various placental histopathological changes were found like chorangiosis (9\%), calcification $(2 \%)$, chorioamnionitis $(2 \%)$, placental infarction $(3 \%)$.

In this study, the mean birth weight was found maximum (1958 gm) in the group with normal Doppler findings (33\% cases) and minimum (1519 gm) in those with reversal of umbilical artery flow. The perinatal outcome was found to be worse in cases with umbilical artery flow changes as compared to those with uterine artery flow changes with maximum neonatal complications requiring NICU admissions (100\%) and consequently maximum perinatal mortality $(77 \%)$ in cases with absent or reversal of flow in umbilical artery. Those with normal Doppler findings had minimal complications (Table 2).

Table No 2: Correlation of Abnormal Doppler findings with Perinatal outcome.

\begin{tabular}{|c|c|c|c|c|}
\hline Doppler changes & $\begin{array}{l}\text { LSCS } \\
(\%)\end{array}$ & $\begin{array}{l}\text { NICU } \\
\text { admission (\%) }\end{array}$ & $\begin{array}{l}\text { Perinatal } \\
\text { mortality (\%) }\end{array}$ & $\begin{array}{l}\text { Neonatal } \\
\text { complication }(\%)\end{array}$ \\
\hline Notch in Uterine Artery(A) & 38.9 & 66.7 & 16.7 & 33.3 \\
\hline Increased S/D ratio in Uterine Artery (B) & 57.1 & 42.9 & 0 & 35.7 \\
\hline Increased S/D ratio in Umbilical Artery (C) & 66.7 & 66.7 & 14.3 & 42.9 \\
\hline Absent Diastolic flow in Umbilical Artery (D) & 71.4 & 85.7 & 57.1 & 85.7 \\
\hline Reversal of flow in Umbilical Artery (E) & 100 & 80 & 20 & 60 \\
\hline Decreased S/D ratio in Middle Cerebral Artery $(\mathrm{F})$ & 100 & 100 & 0 & 50 \\
\hline Normal & 54.5 & 30.3 & 6.1 & 18.2 \\
\hline Total & 59 & 54 & 13 & 36 \\
\hline
\end{tabular}

In the present study, we found maternal complications like PPH (10\%), coagulopathy $(6 \%)$, and other complications like wound gape, acute renal failure, peripartum cardiomyopathy, status eclampticus, puerperal pyrexia, gluteal abscess, urinary tract Infections secondary to anemia, PIH or other comorbid high risk factors like jaundice, thrombocytopenia, HELLP, DIC requiring transfusion of blood and blood products like Whole blood, PCV or Platelets ( RDPs). However, all cases were managed well and were discharged after recovery of their respective ailments with $0 \%$ maternal mortality.

In the present study, $83 \%$ cases were found to have asymmetric IUGR while $17 \%$ cases had symmetric IUGR. The Mean birth weight of Asymmetric IUGR cases was less and had higher perinatal mortality (13\%) than Symmetric IUGR cases. 59\% cases had to undergo 
Caesarean section and out of all vaginal deliveries, $51.2 \%$ cases delivered spontaneously while $47 \%$ cases had to be induced, either by prostaglandins or by oxytocics. The most common indication for LSCS in the present study was found to be abnormal Doppler findings (23.72\%) followed by severe oligohydramnios $(22.03 \%)$ and fetal distress $(18.64 \%)$.

In the present study maximum number of babies $(61 \%)$ had mild IUGR with birth weight within $1.5-2.5 \mathrm{~kg}, 25 \%$ cases had moderate IUGR birth weight $1-1.5 \mathrm{~kg}$ and $5 \%$ cases had severe IUGR, weight less than $1 \mathrm{~kg}$.

$47.3 \%$ cases out of all live born babies required NICU admissions and were found to have complications like birth asphyxia, sepsis, respiratory distress syndrome, hyperbilirubinemia, hypoglycaemia, seizures, necrotizing enterocolitis, intraventricular haemorrhage, need of ventilatory support while few of them had congenital anomalies like congenital heart disease, skeletal abnormalities, pelvicalyceal system fullness (Table 3).

\section{Table No 3: Neonatal complications in IUGR}

\begin{tabular}{|l|l|}
\hline Complication & No of cases \\
\hline Respiratory Distress Syndrome & 08 \\
\hline Sepsis & 26 \\
\hline Birth Asphyxia & 02 \\
\hline Hyperbilirubinemia & 05 \\
\hline Congenital anomaly & 04 \\
\hline Hypoglycaemia & 03 \\
\hline Necrotising Enterocolitis & 01 \\
\hline Seizures & 04 \\
\hline Intraventricular haemorrhage & 01 \\
\hline
\end{tabular}

In the present study, the Perinatal Mortality Rate was found to be 1.92 per 1000 live births with 5\% still births and $8 \%$ neonatal deaths, the most common causes of neonatal death being sepsis $(44.4 \%)$ and respiratory distress syndrome $(44.4 \%)$. $87 \%$ babies were discharged along with mother and advised follow up and immunization (Table 4).

\section{Table No 4: Perinatal Outcome IN IUGR cases}

\begin{tabular}{|lc|}
\hline Final outcome of baby & Frequency \\
\hline Discharged & 87 \\
\hline FSB & 03 \\
\hline MSB & 02 \\
\hline NND & 08 \\
\hline Total & 100 \\
\hline
\end{tabular}

Maximum number of cases $48 \%$ was in the age group of 21 to 25 years of age, as this is the optimum age of reproduction in India. 10 cases $(21.85 \%)$ out of these were symmetrical IUGR while 38 cases $(79.16 \%)$ were asymmetrical IUGR. There was a total of 110 babies in the study including 3 sets of twins. There were 46 $(41.8 \%)$ babies with IUGR. Eleven major adverse outcomes were noted in the study- 2 stillbirths, 6 babies required immediate respiratory support and three babies had respiratory distress subsequently. Of the 6 babies who required immediate resusucitation, one expired in immediate neonatal period due to birth asphyxia (intrapartum fetal distress at 32 weeks in woman with severe preeclampsia), one expired after 10 days due to metabolic complications and the rest four survived.

\section{DISCUSSION}

Brodsky and Cristou refer that the incidence of IUGR is $5-7 \%$. Sharon and Gilberto in their study on 5961 cases found the incidence of IUGR to be $2.4 \%$. In the present study on 100 cases out of 4674 deliveries, the incidence of IUGR was found to be $2.13 \% .^{5-7}$ Sharon and Gilberto analyzed data from a survey of California mothers aged $\geq 15$ years with term live births in 1999 and 2000 ( $\mathrm{N}=$ 5961). They observed that the proportion of IUGR babies was found highest in the age group younger than 20 years. In the present study, maximum number of cases (48\%) were seen in the age group of 21-25 years as this is the usual average age for reproduction in India. ${ }^{8}$

Radhakrishnan $\mathrm{T}$ et al in their study on 280 infants and their mothers stated that Low Socio-Economic status appears to be the principal predictor of Low Birth Weight, and it is associated with 3.5-fold-elevated risk of Low Birth Weight in the babies compared to High SocioEconomic status of the mother. In the present study, 76\% cases of IUGR came from lower socioeconomic class (<1000 per month). ${ }^{9}$

Villalbi JR and Salvador $\mathrm{J}$, in their study showed that IUGR were more frequent among women with a manual occupation. T. Aghamolaei, and H. Eftekhar in their study of 60 cases of IUGR and 60 controls have shown that maximum number of cases 53 were housewives and 8 mothers did clerical works. In the present study 75 (75 $\%)$ cases were housewives, 13 (13\%) cases were labourer by occupation and $12(12 \%)$ cases had sedentary jobs. ${ }^{10,11}$

D. Acharya and K. Nagraj in their study of 101 cases of IUGR and 202 controls showed that $44(43.6 \%)$ cases were primigravida and $57(33.7 \%)$ cases were multigravida. $^{12}$

Rachdi R and Chlyah M in their study of 124 cases of IUGR have shown that $46.8 \%$ mothers were primiparous. Ferraz et. al in Brazil and Malvankar et al in their studies have proved primiparity as one of the determinants of IUGR. In the present study out of 100 cases, 55 (55\%) cases were Primigravida. As per study by K. S. Negi, cases registered in $3^{\text {rd }}$ Trimester had the highest risk $(29.2 \%)$ of delivering baby with IUGR. Of all the registered cases, MBW was least (1719 gm) in cases who were registered in third trimester and maximum (1898 gm) in cases registered in first trimester. Thus, early antenatal registration and regular antenatal checkup is a 
very important step towards better maternal and neonatal outcome. S Sinha, in his study has stated that outcome of pregnancies in terms of foetal growth restriction improve significantly for women who have at least two antenatal checkups. In the present study, Least MBW (1602 gm) was seen in unregistered cases followed by cases with less than 3 visits (1791 gm). As the number of antenatal visits increased, MBW also increased, again emphasizing the fact that antenatal care as early as possible will help improve the birthweight for increased salvagability of the infant. ${ }^{13-15}$

Visser et al found Hypertensive Disorder to be the most common causative factor for IUGR accounting for $59 \%$ of the cases. In the present study, $55 \%$ cases had preeclampsia and eclampsia with least Mean Birth weight of $1633 \mathrm{gm}$ and $1672 \mathrm{gm}$ respectively and subsequently a poor Perinatal Outcome compared to others.

Dr. Field et al. in his studies has shown that fundal height measurement usually a routine part of prenatal care--has a sensitivity of $70 \%$ for intrauterine growth restriction (IUGR). In the present study, Symphysio- Fundal Height was small for gestational age in $76 \%$ cases and was found to be a sensitive predictor of IUGR ${ }^{15}$ As per study by Hadlock F., the ratio of head circumference to abdominal circumference is normally one at 32 to 34 weeks and falls below one after 34 weeks. A ratio of greater than one detects about 85 percent of growthrestricted Fetuses.17 In this study, $80 \%$ cases had $\mathrm{HC} / \mathrm{AC}$ ratio more than $1(\mathrm{P}=0.000)$

Highly significant increase in the incidence of infarction, intervillous fibrin deposition, stromal fibrosis, and syncytial knotting were found in placentas of newborns with Intrauterine Growth Restriction and in placentae of hypertensive mothers compared to full-term normal placenta was seen in the study by Mardi K et al. ${ }^{16}$

In the present study, chorangiosis was seen in $9(9 \%)$ cases while other placental changes found were calcification, chorioamnionitis and infarction. As per Queenan JT et al (1994)17, about 85 percent of IUGR infants have oligohydramnios. In this study $57(57 \%)$ cases were found to have oligohydramnios (AFI $<7 \mathrm{cms}$ ).

Hershkovitz et al. studied MCA Doppler findings in small fetuses (Forty-seven fetuses) and found that those fetuses with abnormal MCA study results had earlier deliveries, lower birth weights, fewer vaginal deliveries, and increased admissions to neonatal ICUs. In this study, the neonatal complications and perinatal outcome were worse in cases with umbilical artery flow changes and Perinatal mortality was maximum $(77 \%)$ in cases with absent or reversal of flow.

Dashe et al in his study on 1364 SGA infants found that $20 \%$ i.e. 273 were asymmetrically grown while $80 \%$ i.e.1091 symmetrically grown. A neonatal outcome composite, including one or more of Respiratory Distress,
Intraventricular Hemorrhage, Sepsis, or Neonatal Death, was more frequent among asymmetric SGA than AGA infants $(14 \%$ versus $5 \%, \mathrm{P}=.001)$. In this study ,83\% cases had asymmetrical IUGR while $17 \%$ cases had symmetrical IUGR. The Mean birth weight of Asymmetric IUGR cases was less and had higher perinatal mortality $(13 \%)$ than Symmetric IUGR cases. ${ }^{18}$

Sood et al in their study found the percentage of LSCS to be $35 \%$ in symmetrical and $29 \%$ in asymmetrical IUGR. In the present study ,59\% cases had to undergo Caesarean section and the most common indication for LSCS was found to be abnormal Doppler findings (23.72\%) followed by severe oligohydramnios $(22.03 \%)$ and fetal distress (18.64 \%). According to Cloherty et al, congenital anomalies, perinatal asphyxia, meconium aspiration, pulmonary hemorrhage, persistent pulmonary hypertension, hypothermia, hypoglycemia, hypocalcemia and hyponatremia are common in IUGR babies.

In the present study, Out of 54 NICU admissions ,26 babies developed sepsis during their NICU stay, others developed Respiratory Distress Syndrome, birth asphyxia, hyperbilirubinemia , hypoglycemic attacks, seizures, necrotizing enterocolitis and intraventricular hemorrhage. $4 \%$ babies had congenital anomalies. Cunningham FG et al in their study concluded that there is 5 to 30 times greater perinatal mortality if birthweight is less than $2500 \mathrm{gm}$.

In the present study, $61 \%$ cases had birth weight within $1.5-2.5 \mathrm{~kg}, 25 \%$ cases had birth weight $1-1.5 \mathrm{~kg}$ and $5 \%$ cases had weight less than $1 \mathrm{~kg}$. Out of these, $54 \%$ cases required NICU admission, $36 \%$ cases developed neonatal complications and $19 \%$ cases required ventilatory supports. There were $5 \%$ still births and $8 \%$ neonatal deaths, the most common causes of neonatal death being sepsis (44.4\%) and respiratory distress syndrome (44.4\%)

\section{CONCLUSION}

IUGR is a common obstetric complication and is often not diagnosed antenatally. Hence accurate dating, provision of early registration with regular antenatal check-up, clinico- sonographic evaluation and correlation for fetal growth in high risk patients and strict antepartum surveillance after IUGR has been identified are recommended.

Doppler studies have been accepted as an integral part of protocols to assess IUGR while labor and delivery in IUGR babies need to be monitored and managed meticulously and aggressively and be attended by a qualified neonatologist keeping lower threshold for the choice of caesarean section.

Funding: No funding sources Conflict of interest: None declared

Ethical approval: The study was approved by the Institutional Ethics Committee 


\section{REFERENCES}

1. Sharma D, Shastri S, Sharma P; Intrauterine Growth Restriction: Antenatal and Postnatal Aspects. Clin Med Insights Pediatr. 2016;10:67-83.

2. Bernstein I, Gabbe SG. Intrauterine growth restriction. Obstetrics: normal and problem pregnancies. $3^{\text {rd }}$ ed. New York: Churchill Livingstone, 1996:863-86.

3. Wolfe HM, Gross TL. Increased risk to the growth retarded fetus. In: Gross TL, Sokol RJ, eds. Intrauterine growth retardation: a practical approach. Chicago: Year Book Medical Publishers, 1989:11124.

4. Fetal growth restriction. In: Cunningham FG, et al., eds. Williams Obstetrics. $20^{\text {th }}$ ed. Stamford, Conn.: Appleton and Lange, 1997:839-54.

5. Lin CC, Santolaya-Forgas J. Current concepts of fetal growth restriction: part I Causes, classification, and pathophysiology. Obstet Gynecol. 1998;92: 1044-55.

6. Creasy RK, Resnik R. Intrauterine growth restriction. In: Creasy RK, Resnik R,eds. Maternal-fetal medicine: principles and practice. $3 \mathrm{~d}$ ed. Philadelphia: Saunders, 1994;558-74

7. Gardosi J. New definition of small for gestational age based on fetal growth potential. Horm Res 2006; 65:15.

8. Sharon D, Gilberto FC. Associations of intrauterine growth restriction among term infants and maternal pregnancy intendedness, initial happiness about being pregnant and sense of control, Pediatr. 2003;111:1171-5.

9. Radhakrishnan T, Thankappan KR, Vasan RS, Sarma PS, Socioeconomic and demographic factors associated with birth weight. A community-based study in Kerala, Indian Pediatr. 2000;37:872-6.
10. Villalbí JR, Salvador J, Cano-SG, Rodríguez-Sanz MC, Borrell C. Pediatric Perinatal Maternal smoking, social class and outcomes of pregnancy. Epidemiol. 2007;21:441-7.

11. Aghamolaei T, Eftekhar H, Aghamolaei SZ. T, Risk Factors Associated with Intrauterine growth Retardation (IUGR) in Bandar Abbas. J Medical Sci. 2007;7:665-9.

12. D Acharya, K Nagraj. Case study conducted in Karnataka in 2004 on Maternal Determinants of Intrauterine growth restriction, Indian $\mathrm{J}$ Clini Biochem. 2006;21:111-5.

13. Rachdi R, Chlyah M, Messaoudi F, Kallel M, Yazidi M, Basly M, et al. Maternal and foetal indicators of oxidative stress during Intrauterine growth retardation, Indian J Clinical Biochem. 2006;21:1115.

14. Sinha S. Outcome of antenatal care in an urban slum of Delhi. Indian J Commun Med. 2006;31:189-91.

15. Barbara Boughton Fundal height measures for IUGR often unreliable. OB/GYN News, 2010.

16. Manning FA, Harman CR, Fetal assessment based on Fetal Biophysical Profile Scoring. AM Jr Obstet and Gynaecol. 1987;157-880.

17. Walton A, Hammond $\mathrm{J}$ classical horse pony crossbreed exp. Jr. Animal Sci. 2000;4:312-30.

18. Dashe JS, Mcintire DD, Effects of symmetrical and asymmetrical growth on pregnancy outcome, Obstet Gynecol. 2000;96:321-27.

Cite this article as: Sinha S, Kurude VN. Study of obstetric outcome in pregnancies with intrauterine growth retardation. Int J Reprod Contracept Obstet Gynecol 2018;7:1858-63. 